\title{
Uncertainties in the national inventory of methane emissions from rice cultivation: field measurements and modeling approaches
}

\author{
Wen Zhang ${ }^{1}$, Wenjuan $\mathrm{Sun}^{2}$, and Tingting $\mathrm{Li}^{1}$ \\ ${ }^{1}$ LAPC, Institute of Atmospheric Physics, Chinese Academy of Sciences, Beijing, China \\ ${ }^{2}$ LVEC, Institute of Botany, Chinese Academy of Sciences, Beijing, China \\ Correspondence to: Wenjuan Sun (sunwj@ibcas.ac.cn)
}

Received: 10 June 2016 - Published in Biogeosciences Discuss.: 27 July 2016

Revised: 8 December 2016 - Accepted: 16 December 2016 - Published: 12 January 2017

\begin{abstract}
Uncertainties in national inventories originate from a variety of sources, including methodological failures, errors, and insufficiency of supporting data. In this study, we analyzed these sources and their contribution to uncertainty in the national inventory of rice paddy methane emissions in China and compared the differences in the approaches used (e.g., direct measurements, simple regressions, and more complicated models). For the 495 field measurements we collected from the scientific literature, the area-weighted $95 \% \mathrm{CI}$ (confidence interval) ranged from 13.7 to $1115.4 \mathrm{~kg} \mathrm{CH}_{4} \mathrm{ha}^{-1}$, and the histogram distribution of the measurements agreed well with parameterized gamma distributions. For the models, we compared the performance of methods of different complexity (i.e., the CH4MOD model, representing a complicated method, and two less complex statistical regression models taken from literature) to evaluate the uncertainties associated with model performance as well as the quality and accessibility of the regional datasets. Comparisons revealed that the CH4MOD model may perform worse than the comparatively simple regression models when no sufficient input data for the model is available. As simulated by CH4MOD with data of irrigation, organic matter incorporation, and soil properties of rice paddies, the modeling methane fluxes varied from 17.2 to $708.3 \mathrm{~kg} \mathrm{CH}_{4} \mathrm{ha}^{-1}$, covering $63 \%$ of the range of the field measurements. When applying the modeling approach to the $10 \mathrm{~km} \times 10 \mathrm{~km}$ gridded dataset of the model input variables, the within-grid variations, made via the Monte Carlo method, were found to be $81.2-95.5 \%$ of the grid means. Upscaling the grid estimates to the national inventory, the total methane emission from the rice paddies was 6.43 (3.799.77) $\mathrm{Tg}$. The fallacy of CH4MOD contributed $56.6 \%$ of the
\end{abstract}

total uncertainty, with the remaining $43.4 \%$ being attributed to errors and the scarcity of the spatial datasets of the model inputs. Our analysis reveals the dilemma between model performance and data availability when using a modeling approach: a model with better performance may help in reducing uncertainty caused by model fallacy but increases the uncertainty caused by data scarcity since greater levels of input are needed to improve performance. Reducing the total uncertainty in the national methane inventory depends on a better understanding of both the complexity of the mechanisms of methane emission and the spatial correlations of the factors that influence methane emissions from rice paddies.

\section{Introduction}

Rice cultivation is a major source of anthropogenic methane and a prime target of greenhouse gas mitigation efforts (Tian et al., 2016; Smith et al., 2008). Globally, the methane emission from rice cultivation was about $18.3 \mathrm{Tg} \mathrm{CH}_{4} \mathrm{yr}^{-1}$ under intermittent irrigation and $38.8 \mathrm{Tg} \mathrm{CH}_{4} \mathrm{yr}^{-1}$ under continuous flooding in the 2000s (Zhang et al., 2016). Methane fluxes in rice paddies varied extensively with environmental and agronomic factors. Certain factors, such as rice biomass (Bachelet and Neue, 1993), organic matter input (Kern et al., 1995), water management (Khosa et al., 2011; Mishra et al., 1997), paddy soil properties (Yao et al., 1999; Gaunt et al., 1997), climate (Sass et al., 1991), and rice varieties (Su et al., 2015; Ding et al., 1999), have been recognized as having significant impacts on methane emissions. Other factors, such as atmospheric $\mathrm{CO}_{2}$ and ozone contents (Dijkstra et al., 2012; Bhatia et al., 2011; Inubushi et al., 2011), N fertilizer 
application (Banger et al., 2012; Xie et al., 2010a), and active soil organic C (Zhan et al., 2011), and even the field management of rotation crops (Weller et al., 2016), are also receiving increasing attention. Because so many factors affect the production, oxidation, and emission of methane from rice cultivation, the observed methane fluxes varied extensively both spatially and temporally.

Numerous methods have been applied for estimating national and global inventories of rice paddy methane emissions, including metanalysis of direct measurements, process models, and empirically based statistical models. However, the range of national and/or global source estimates remains large (Cao et al., 1996; Sass et al., 1999; Chen et al., 2013). The major factors that are known to regulate rice paddy methane emissions include agricultural management practices (Khosa et al., 2011; Sanchis et al., 2012; Sass et al., 1992; Bodelier and Laanbroek, 2006) and environmental conditions, such as climate and soil properties (Conrad et al., 2007; Inubushi et al., 2011; Sass et al., 1991). Currently, techniques for calculating methane emissions differ substantially and usually consist of scenario simulations (Ito and Inatomi, 2012; Van Bodegom et al., 2002a, b; Verburg et al., 2006), without integrated consideration of methodological fallacy and data insufficiency.

By extrapolating field measurements obtained from experiments, methane emissions from the 30 million ha of land under rice cultivation in China were estimated to range from 21.6 to $30 \mathrm{Tg} \mathrm{CH}_{4} \mathrm{yr}^{-1}$ (Matthews et al., 1991; Taylor et al., 1991), much larger than the result of a recent study (Zhang et al., 2016). The extrapolation of methane emission rates from site measurements to larger regions is unlikely to yield reliable results because of the tremendous spatial heterogeneity in environmental conditions and agronomic activities (Ogle et al., 2010). Other studies have described the relationships between methane emissions and rice NPP (net primary productivity) (Bachelet and Neue, 1993) and organic matter inputs (Bachelet et al., 1995). Ambient temperature and the use of nitrogen $(\mathrm{N})$ fertilizer have also been identified as determinants of methane emissions (Kern et al., 1995; Bachelet et al., 1995). Until the significant reduction in methane emissions caused by mid-season drainage was confirmed (Sass and Fisher, 1997; Yagi et al., 1997; Li et al., 2002; Yan et al., 2005), all previous regional and national estimates (obtained using extrapolation or regression equations) were derived from continuously flooded rice fields. More factors, such as the (Watanabe et al., 1995; Butterbach-Bahl et al., 1997; Ding et al., 1999; Inubushi et al., 2011) soil properties (Sass et al., 1994; Yao et al., 1999), atmospheric $\mathrm{CO}_{2}$ (Dijkstra et al., 2012; Xie et al., 2010b), and ozone (Bhatia et al., 2011) concentrations involved in rice cultivation, have also been incorporated into models designed to estimate methane emissions from rice paddies. Complex interactions among these factors have spurred model development (Cao et al., 1995; Li, 2000; Matthews et al., 2001; Huang et al., 1998, 2004; Van Bodegom et al., 2001). To delineate variations in methane emissions and to reduce uncertainties, the impacts of these factors on the production, oxidation, and emission of methane were mathematically incorporated into the models. Models with more factors are able to reduce uncertainties in estimating methane emissions, but the estimates generated by these models still differ significantly across multiple spatial and temporal scales (Butenhoff et al., 2009; Ren et al., 2011; Chen et al., 2013).

Reduction of the uncertainty in estimated methane emissions requires the development of an effective and reliable model that incorporates various paddy environments and agronomic activities. However, our understanding of the complex biogeochemical processes that occur in paddy soils is poor. When estimating methane emissions from rice agriculture, only factors that are thought to be key determinants of methane emissions have been incorporated into the models. Excluding other factors introduces errors into the model output (Eqs. S6 and S7 in the Supplement). Improving our knowledge of methane processes in the future will increase the number of factors that are integrated into models and potentially delineate details related to spatiotemporal variations.

Uncertainties in regional estimates of methane emissions from rice paddies stem not only from fallacy in the applied models but also from errors and inadequate data, which we discussed in a previous study (Zhang et al., 2014; Sect. S4 in the Supplement). A model with more factors generally performs better than a model with fewer factors but requires a larger amount of data to facilitate model application. A model with good performance (less fallacy) can still result in large uncertainties when the available input data (e.g., soil properties, rice irrigation, types and amount of organic matter) are insufficient (Zhang et al., 2014; Ito et al., 2012).

In the present study, we analyzed the uncertainties in experimental measurements of methane fluxes in different rice paddies. We also evaluated the performance of different methods involving a diversity of input variables and the influence of data availability on the performance of these methods. Finally, the uncertainty in the national emissions inventory as a consequence of variable model performance and according to the quality and availability of input data was discussed.

\section{Materials and methods}

\subsection{Field measurements of methane emissions from rice paddies in China}

The observational data used in this study (Table 1) consisted of field methane fluxes measured at 33 sites (Fig. 1). We obtained these measurements from the published literature concerning all crop rotations with rice cultivation in China (double rice, winter wheat, and rice rotation; single rice crop cultivation; and so forth) (Wei, 2012). A total of 495 mea- 
Table 1. Methods and their input scenarios.

\begin{tabular}{|c|c|c|}
\hline Methods & Input scenario & Reference \\
\hline $\mathrm{R} 1: C_{\mathrm{CH}_{4}}=0.3 \times C_{\text {input }}$ & R1-S0: case-specific C input, adjusted with the water regime ${ }^{\mathrm{a}}$. & Neue et al. (1990) \\
\hline $\begin{array}{l}\mathrm{R} 2: \mathrm{CH}_{4}=-0.006 \times C_{\text {input }} \\
\quad+0.078 \times N_{\text {input }} \\
\quad+0.885 \times R_{\mathrm{C} / \mathrm{N}}+21.15\end{array}$ & $\begin{array}{l}\mathrm{R} 2-\mathrm{S} 0 \text { : case-specific } \mathrm{C} \text { and } \mathrm{N} \text { input. } \\
\mathrm{R} 2-\mathrm{S} 1 \text { : case-specific } \mathrm{C} \text { input, averaged } \mathrm{N} \text { input in all cases. }\end{array}$ & Kern et al. (1997) \\
\hline M: CH4MOD model & $\begin{array}{l}\text { M-S0: case-specific inputs of all model variables: e.g., organic matter } \\
\text { amendments, soil properties, and water regimes }{ }^{b} \text {. } \\
\text { M-S1: case-specific inputs of soil properties and water regimes; other } \\
\text { model variables use averaged values for all } 495 \text { cases. } \\
\text { M-S2: case-specific inputs of organic matter amendments; all other } \\
\text { model variables use averaged values for all } 495 \text { cases; the water regime } \\
\text { was assumed to be multi-drainage irrigation. } \\
\text { M-S3: no case-specific inputs used for soil properties or organic mat- } \\
\text { ter amendments; the water regime was assumed to be multi-drainage } \\
\text { irrigation. }\end{array}$ & $\begin{array}{l}\text { Huang et al. (1998, 2004); } \\
\text { Xie et al. (2010a) }\end{array}$ \\
\hline
\end{tabular}

\footnotetext{
${ }^{\text {a }}$ Regression equation R1 was developed according to measurements conducted in continuously flooded fields, and the calculated flux was therefore adjusted by a scaling factor of $1.00,0.65$, or 0.56 for continuous flooding, single drainage, or multi-drainage irrigation, respectively (IPCC, 2006). ${ }^{\mathrm{b}}$ The water regimes in the CH4MOD model (Huang et al., 2004) are more specifically defined and differ from those of the IPCC (2006).
}

surements were taken at the 33 sites, after excluding those that had been used for the model calibration (Neue et al., 1990; Kern et al., 1997; Huang et al., 2004). The amount of organic matter added to the rice paddies ranged from 0 to $15.3 \mathrm{t} \mathrm{C} \mathrm{ha}^{-1}$ and included animal manure, green manure, crop straw, biogas residuals, and their various components. The applied water regimes consisted of continuous flooding, single mid-season drainage, and multi-drainage irrigations.

Model performance was assessed by comparing the model estimates with the measurements. To drive the models, data pertaining to rice yields, soil properties, and crop phenologies were collected from the relevant literature (Sect. S2 in the Supplement).

\subsection{Performance of the methods used to estimate methane emissions}

The uncertainties produced by the models derive from model fallacy (Kennedy and O'Hagan, 2001; Sect. S3 in the Supplement) as well as from the quality and availability of data (Fig. 2). Model performance was assessed by comparing model outputs with the direct measurements (left part in Fig. 2). Errors in the input data of the model can be propagated in the obtained estimates (right side of Fig. 2, Sect. S4 in the Supplement).

Many techniques are available for calculating estimates of rice paddy methane emissions, such as extrapolation of measured emission rates (Khalil et al., 1991, 1993), statistical regression equations (Bachelet et al., 1995; Kern et al., 1995, 1997), and the application of models of varying complexity (Cao et al., 1995; Matthews et al., 2001; Van Bodegom et al., 2001; Huang et al., 1998; Li, 2000). Here we chose two regression models (Neue et al., 1990; Kern et al., 1997)

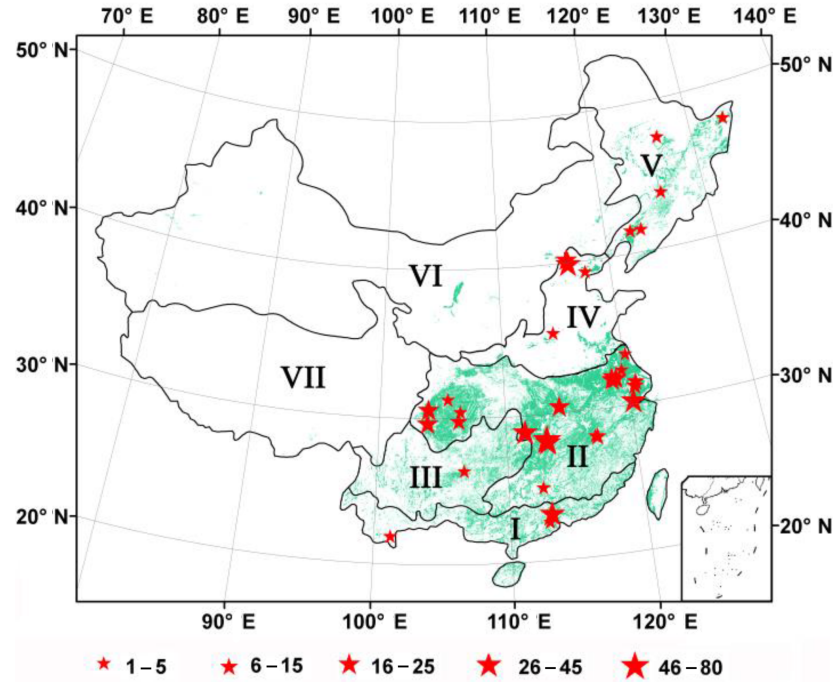

Figure 1. Locations of the experimental sites (red stars). The background map represents the spatial distribution of rice paddies in China. The size of the red stars is proportional to the number of measured methane fluxes at the site. The polygons show zones of different crop rotation systems involving rice: I - double rice rotation, II - mixed zone of rice and rice rotation and rice and upland crop rotation, III \& IV - rice and upland crop rotation or rice and fallow rotation, V \& VI - rice and fallow rotation, and VII - no rice.

and CH4MOD (Huang et al., 2004) because they differed explicitly in levels of structural complexity. We compared the performance of these methods under different levels of data availability (Table 1) using experimental field measurements as a point of reference (Fig. 1). In Table 1, R1 represents a simple regression equation in which the carbon (C) input is 


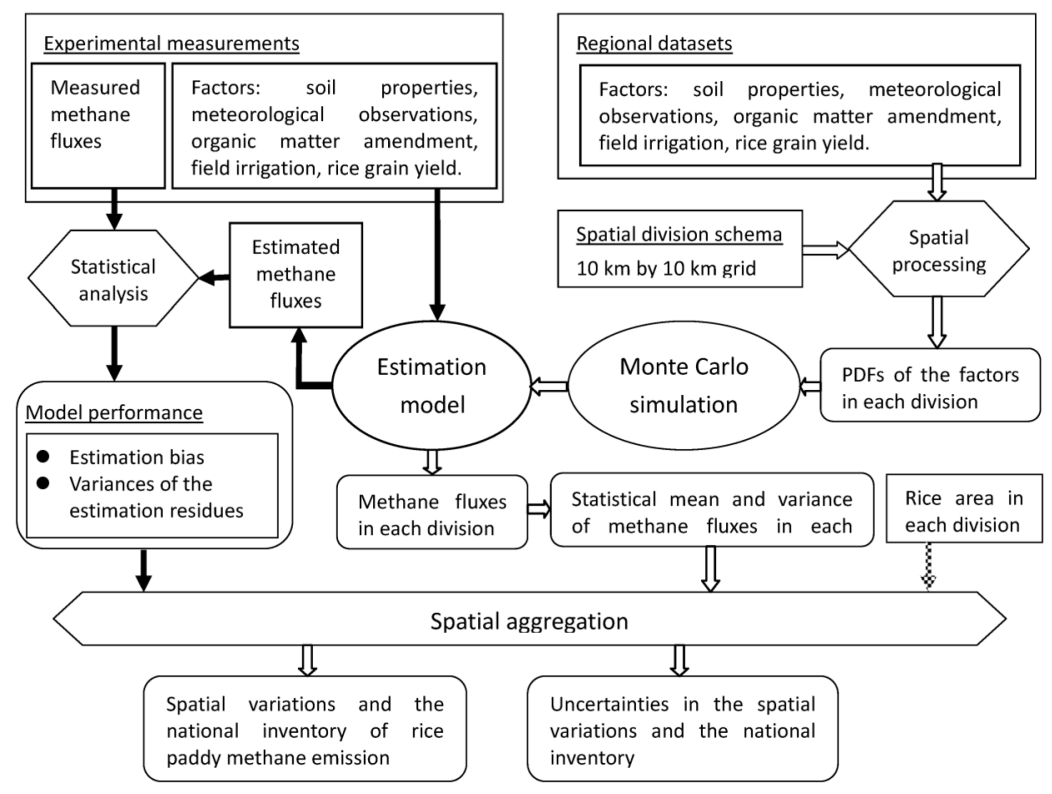

Figure 2. Flowchart for estimating regional and national methane emissions and the uncertainties associated with field measurements and modeling.

the sole predictor (Neue et al., 1990). Regression equation $\mathrm{R} 2$ is slightly more complicated in that it uses organic $\mathrm{C}$ and fertilizer $\mathrm{N}$ application as inputs (Kern et al., 1997). We assumed two data availability scenarios for R2. In R2-S0, both the $\mathrm{C}$ and $\mathrm{N}$ inputs are available; in $\mathrm{R} 2-\mathrm{S} 1$, only the $\mathrm{C}$ input is available (Table 1).

The third approach consists of a semiempirical model, CH4MOD. This model was developed to simulate methane emissions from rice paddies under diverse environmental conditions and various agricultural practices (Huang et al., 1998, 2004). The input variables of the model include the climate, soil conditions, water management type, organic matter application, and crop rotations. The model consists of two modules: the derivation of methanogenic substrates from added organic matter and rice root exudates and the production and emission of methane. Rice biomass is a key variable used to calculate the root exudates and the fraction of the methane emitted by rice plants and bubbles. The daily changes in the soil redox potential (Eh) were calculated according to various water manipulations conducted in the rice paddies (Xie et al., 2010b). The influences of other environmental factors, such as soil temperature and texture, on the decomposition of organic matter and the production of methane were expressed as specific coefficient functions (Huang et al., 1998). The input variables of the CH4MOD model (Sect. S2 in the Supplement) include the daily air temperature, soil sand percentage (SAND), organic matter amendment $(\mathrm{OM})$, rice grain yield (GY), water management pattern $\left(W_{\text {ptn }}\right)$, and rice cultivar index $(\mathrm{VI})$.

Four model input scenarios (Table 1) were scheduled to evaluate the performance of CH4MOD under different levels of data availability. In M-S0, all of the model variables were assigned specific values. In M-S1, the application of organic matter was assigned the average value for all experiments, thus assuming a situation where no detailed information on organic matter application was available. In M-S2, detailed information on the water regime and soil properties was assumed to be unavailable. In M-S3, detailed information on all three major factors (organic matter application, soil properties, and water regime) was assumed to be unavailable.

The estimation residuals $(\Delta y$, Eq. 1$)$, relative bias $\left(r_{\mathrm{b}}\right.$, Eq. 2), and coefficient of variations ( $r_{\mathrm{v}}$, Eq. 3 ) were thus evaluated as follows:

$$
\begin{aligned}
& \Delta y_{k}=\hat{y}_{k}-y_{k}, \quad i=1,2, \ldots, n \\
& r_{\mathrm{b}}=\frac{E(\Delta y)}{E(y)} \times 100 \% \\
& r_{\mathrm{v}}=\frac{\sqrt{E\left((\Delta y)^{2}\right)-(E(\Delta y))^{2}}}{E(y)} \times 100 \%,
\end{aligned}
$$

where $y$ represents the measured methane fluxes, $\hat{y}$ is the estimate of $y$, and $n$ is the total number of measurements. $E(\cdot)$ indicates the statistical mean. The mean of the squared errors (MSE) of the estimation is calculated as follows:

$$
\begin{aligned}
\mathrm{MSE} & =E\left((\Delta y)^{2}\right)=\left(E\left((\Delta y)^{2}\right)-(E(\Delta y))^{2}\right)+(E(\Delta y))^{2} \\
& =\left(F \times r_{\mathrm{v}}\right)^{2}+\left(F \times r_{\mathrm{b}}\right)^{2},
\end{aligned}
$$

where $F=E(y)$ represents the mean of the measured methane fluxes $\left(y_{k}\right)$. 


\subsection{Uncertainties in estimating rice paddy methane emissions on national scales: data error and availability}

In addition to model fallacy, the difficulties in estimating national rice paddy methane emissions also stem from errors in, and limited availability of, input data. To measure the uncertainties in model outputs due to insufficient data quality and availability, we applied Monte Carlo simulations (Penman, 2000) to the CH4MOD model. Statistical characteristics were derived from the available datasets to develop probability distribution functions (PDFs) for each model input variable (Tables S1 and S2 of Sect. S2 in the Supplement). We performed Monte Carlo simulations by randomly drawing values of the model input variables from their PDFs and then running the model. This process was iterated 1000 times and at the last step the mean and $95 \% \mathrm{CI}$ (confidence interval) of the calculated methane fluxes were derived from the iterations.

The factors involved in the uncertainty analysis included organic matter application, soil properties, and water regimes; these variables (OM, SAND, and $\left.W_{\mathrm{ptn}}\right)$ were parameterized as input variables in the CH4MOD model (Huang et al., 2006; Zhang et al., 2011). The other two model input variables were the rice grain yield and daily ambient air temperature. These two variables were not used in the uncertainty analysis because sufficient relevant data were available, which were characterized by less errors compared with the other variables (Zhang et al., 2014).

The SAND data were obtained from a $10 \mathrm{~km} \times 10 \mathrm{~km}$ grid dataset interpolated from soil survey data (Oberthür et al., 1999; Shi et al., 2004; Liu et al., 2006). It is possible that approximately half (Van Bodegom et al., 2002b) of the immense spatial variation in soil properties can be lost after spatial interpolation (Goovaerts, 2001); as a result, the missing spatial variation was attributed to the PDF of the gridded SAND data (Sect. S2 in the Supplement).

The organic matter inputs in the rice fields consisted of various types of farm manure (green manure and animal feces), crop straw, and dead roots and stubble leftover from previous harvests. Root and straw biomass were calculated using the root/ shoot ratio and harvest indices (Huang et al., 2007; Gao et al., 2002; Xie et al., 2010c). Stubble was assumed to represent $1 / 10$ of the straw biomass (Huang et al., 2004). The proportions of incorporated straw and applied farm manure were derived from data obtained from two large-scale investigations, the First National Census of Pollution Sources conducted by China's Ministry of Environmental Protection (CFPC, 2011) and a census conducted by the Institute of Atmospheric Physics, Chinese Academy of Sciences. The proportion of straw and the amount of manure incorporated into the crop fields were summarized by province. Table $S 1$ shows the statistical parameters of the PDF of organic matter incorporation in each province.
The irrigation in rice cultivation were grouped into five general irrigation patterns: (1) flooding-drainage-floodingintermittent irrigation, (2) flooding-drainage-intermittent irrigation, (3) flooding-intermittent irrigation, (4) continuous flooding, and (5) continuously intermittent irrigation (Gao and $\mathrm{Li}, 1992$; Huang et al., 2004). Data pertaining to $W_{\text {ptn }}$ were only very rarely available on a regional scale. The limited information provided in a few studies (Mao, 1981; Liang, 1983; Xiong et al., 1992; Cai et al., 2003; Ma et al., 2005; MWRUC, 1996) could only yield rough estimates related to irrigation in regions of major rice cultivation. The PDFs of field irrigation were defined by the occurrence percentage of each irrigation pattern (Table S2 in the Supplement).

The data pertaining to the rice grain yield and harvesting area as of 2005 were obtained from China's Statistical Yearbook (EBCAY, 2006) and the nation's agricultural database maintained by the Chinese Academy of Agricultural Sciences, respectively. The spatial distributions of all rice paddies in 2005 and the rice paddy area within each $1 \mathrm{~km} \times 1 \mathrm{~km}$ grid were obtained from the Data Center for Resources and Environmental Sciences of the Chinese Academy of Sciences (RESDC, CAS). Daily mean air temperature data from 678 meteorological stations throughout China for 2005 were acquired from the National Meteorological Information Center (NMIC) of the China Meteorological Administration (CMA) (http://data.cma.cn/). The temperatures were then spatially interpolated into $10 \mathrm{~km} \times 10 \mathrm{~km}$ grids for each day according to the method described by Thornton et al. (1997). Details on the datasets used in this study can be found in Sect. S2.

To preserve details related to spatial variations, all data input into the model were converted into $10 \mathrm{~km} \times 10 \mathrm{~km}$ grids. The applied rasterization techniques and details of how the model was run on raster datasets were provided in previously published papers (Huang et al., 2006).

\subsection{Combining uncertainty and spatial aggregation}

In each $10 \mathrm{~km} \times 10 \mathrm{~km}$ grid, the uncertainties in our estimates originated from both the model fallacy (Eq. 4) and error in the input data. Equation (5) was used to merge the two uncertainty sources where MSE was again split into two parts as showed in Eq. (4):

$$
\begin{aligned}
\sigma_{T, i}^{2} & =\sigma_{\mathrm{b}, i}^{2}+\sigma_{\mathrm{v}, i}^{2}+\sigma_{\mathrm{d}, i}^{2} \\
& =\left(F_{i} \times r_{\mathrm{b}}\right)^{2}+\left(F_{i} \times r_{\mathrm{v}}\right)^{2}+\sigma_{\mathrm{d}, i}^{2},
\end{aligned}
$$

where $\sigma_{T, i}$ represents the uncertainty of the methane flux in grid $i$, and $F_{i}$ and $\sigma_{\mathrm{d}, i}$ represent the mean and standard deviation of the Monte Carlo simulation results in grid $i$, respectively. $r_{\mathrm{b}}$ and $r_{\mathrm{v}}$ represent the same entities as in Eqs. (2) and (3).

$\sigma_{\mathrm{d}, i}^{2}$ signifies the uncertainty caused by the error and availability of data, $\left(F_{i} \times r_{\mathrm{b}}\right)^{2}$ represents the modeling bias, and $\left(F_{i} \times r_{\mathrm{v}}\right)^{2}$ represents the rest parts of the model fallacy apart 

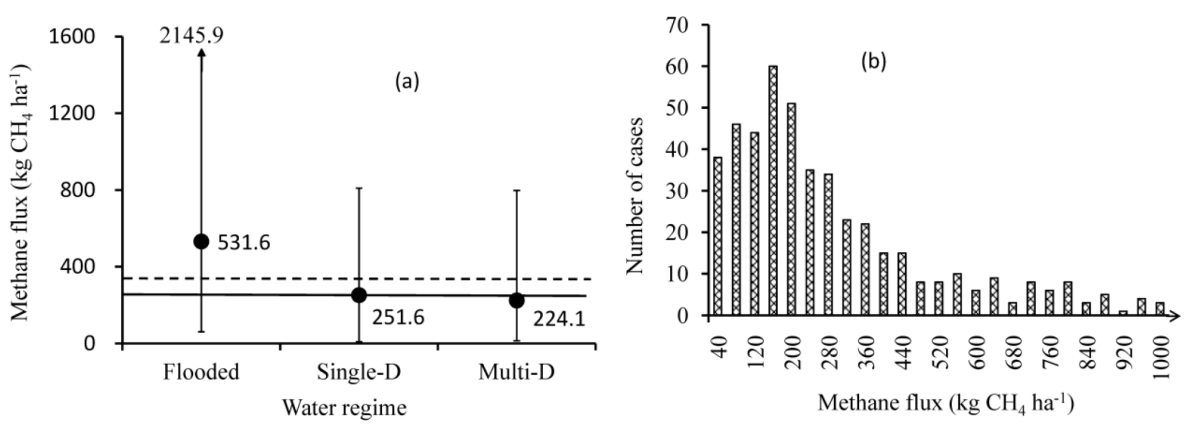

Figure 3. Statistical representations of the measured methane fluxes. (a) Statistical parameters and (b) histogram of the measurements. The solid circles represent the sample mean, and the vertical bars are the $95 \%$ confidence intervals of the samples, from the $2.5 \%$ percentile to the $97.5 \%$ percentile. The dashed line indicates the arithmetic average of all measured fluxes $\left(m_{\mathrm{c}}\right)$. The solid line is the area-weighted mean of the methane fluxes $\left(m_{\mathrm{W}}\right)$, in reference to the areal proportion of each water regime in the national total rice harvesting area: $10 \%$ continuous flooding (Flooded), $20 \%$ single drainage (Single-D), and $70 \%$ multi-drainage (Multi-D) (Xiong et al., 1992; MWRUC, 1996; Li, 2001; Zou et al., 2009).

from $\left(F_{i} \times r_{\mathrm{b}}\right)^{2}$. To produce the uncertainty of the national inventory, the three components $\left(\left(F_{i} \times r_{\mathrm{b}}\right)^{2},\left(F_{i} \times r_{\mathrm{v}}\right)^{2}\right.$, and $\sigma_{\mathrm{d}, i}^{2}$ in Eq. 5) of the estimation uncertainties in all grids were separately aggregated (Eqs. S15, S16, S17, and S18 in Sect. S4 of the Supplement) and summed as follows:

$\sigma_{T}^{2}=\sigma_{\mathrm{b}}^{2}+\sigma_{\mathrm{v}}^{2}+\sigma_{\mathrm{d}}^{2}$.

\section{Results}

\subsection{Methane emissions and the uncertainties derived from field measurements}

Among the 495 methane flux measurements (the accumulative methane emission from transplanting to harvesting), 184 (37\% of all cases) came from paddies that were continuously flooded during the entire rice growing period, 50 ( $10 \%$ of all cases) came from paddies with single midseason drainage, and 261 (53\% of all cases) came from paddies under multi-drainage. The average methane fluxes associated with the three water regimes were $531.6 \pm 512.6$, $251.6 \pm 231.1$, and $224.1 \pm 207.5 \mathrm{~kg} \mathrm{CH}_{4} \mathrm{ha}^{-1}$ (Fig. 3a). The overall arithmetic average of the 495 measurements (represented hereafter by $m_{\mathrm{c}}$ ) was $341.2 \pm 383.2 \mathrm{~kg} \mathrm{CH}_{4} \mathrm{ha}^{-1}$. However, the simple arithmetic average might be a biased representation of the "true" mean methane flux of rice paddies in China since far less than $37 \%$ of the rice paddies in China are continuously flooded. In the literature, 10, 20, and $70 \%$ of the rice area was reported to be under continuous flooding, single drainage, and multi-drainage water regimes, respectively (Xiong et al., 1992; MWRUC, 1996), and the harvested-area-weighted mean (Sect. S1 in the Supplement) of the measured fluxes (represented hereafter by $m_{\mathrm{w}}$ ) was $260.4 \pm 281.6 \mathrm{~kg} \mathrm{CH}_{4} \mathrm{ha}^{-1}$ (Fig. 3a).

The $95 \%$ CIs of the methane flux measurements were 61.1-2145.9, 9.6-809.9, and 14.0-797.7 $\mathrm{kg} \mathrm{CH}_{4} \mathrm{ha}^{-1}$, respectively, for the three water regimes (continuous flooding, single drainage, and multi-drainage in Fig. 3a). The $95 \%$ CI of all combined area-weighted measurements (Sect. S1 in the Supplement) was $13.7-1115.4 \mathrm{~kg} \mathrm{CH}_{4} \mathrm{ha}^{-1}$. The measurements were not normally or symmetrically distributed (Fig. 3b). The P-P plots (Fig. 4) showed that the parameterized gamma distributions matched the sample distributions. The $95 \%$ CIs calculated with the parameterized gamma functions were 16.8-1900.8, 10.4-863.4, and 8.9$774.2 \mathrm{~kg} \mathrm{CH}_{4} \mathrm{ha}^{-1}$, respectively, for the three water regimes (continuous flooding, single drainage, and multi-drainage); these values overlapped the CIs derived directly from the measurements by $88.2,99.9$, and $97.0 \%$, respectively.

The national methane emissions from rice agriculture calculated by multiplying the rice harvesting area (yearbook data in 2005) by the area-weighted mean flux $\left(260.4 \pm 281.6 \mathrm{~kg} \mathrm{CH}_{4} \mathrm{ha}^{-1}\right.$ ) was 7.51 $\mathrm{Tg} \mathrm{CH}_{4}$ (Fig. 3a). When the measurements are statistically independent, the standard error (SE) of the summation is $n-1$ ( $n$ is the sample size of the measurements) times smaller than the standard deviation $\left( \pm 281.6 \mathrm{~kg} \mathrm{CH}_{4} \mathrm{ha}^{-1}\right)$, which consists of the representative and measurement errors of the measured fluxes (Van Bodegom et al., 2002a; Verburg et al., 2006). Assuming that the measurements were statistically independent, the $95 \% \mathrm{CI}$ of the national inventory was $7.20-8.58 \mathrm{Tg} \mathrm{CH}_{4}$ (Eq. S3 in the Supplement). However, the independency assumption is questionable because of the spatial correlations between the spatially correlated background environmental conditions and agricultural activities (Legendre, 1993; Dormann et al., 2007). The equivalent sample size used to calculate SE may be smaller than 495, and the $95 \% \mathrm{CI}$ of the national inventory is therefore larger than that with the independency assumption. 

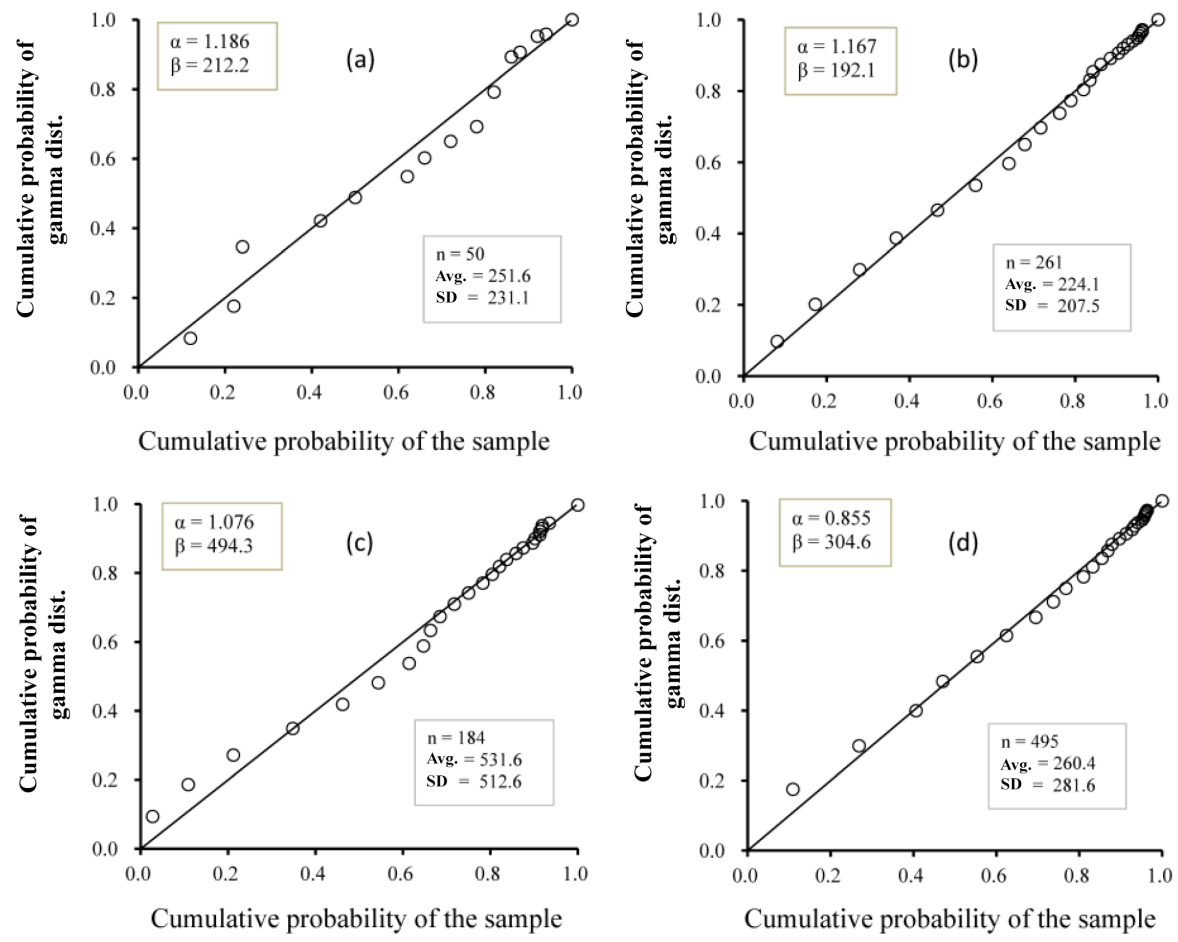

Figure 4. P-P plots of the cumulative probability of the measured methane fluxes vs. the gamma distribution. (a) Single-drainage irrigation cases, (b) multi-drainage irrigation cases, (c) continuous flooding irrigation cases, and (d) all cases after being area weighted (Sect. S1). $n$, avg., and SD represent the sample size, statistical mean, and standard deviation of the sample methane fluxes, respectively. $\alpha$ and $\beta$ represent the shape and scale parameters of the gamma distribution, which were calculated with the statistical mean and variance of the measured methane fluxes; $\beta=(\mathrm{SD})^{2} /($ avg.) and $\alpha=($ avg. $) / \beta$. The diagonal line is the $1: 1$ straight line for a perfect gamma distribution match.

\subsection{Model performance under different situations of data availability}

The averaged bias of the estimate obtained with R1 was $212.0 \mathrm{~kg} \mathrm{CH}_{4} \mathrm{ha}^{-1}$ (Table 2) or $62.1 \%$ of the measured mean $\left(m_{\mathrm{c}}=341.2 \mathrm{~kg} \mathrm{CH}_{4} \mathrm{ha}^{-1}\right)$. The average bias of $\mathrm{R} 2$, in contrast, was $-1.3 \mathrm{~kg} \mathrm{CH}_{4} \mathrm{ha}^{-1}$. R1 was more likely to overestimate the amount of methane emitted than R2 (Table 2), especially when more organic matter was incorporated (Fig. 5a). For example, in one case the modeled $\mathrm{CH}_{4}$ flux was more than $6000 \mathrm{~kg} \mathrm{CH}_{4} \mathrm{ha}^{-1}$, whereas the measured flux was less than $3000 \mathrm{~kg} \mathrm{CH}_{4} \mathrm{ha}^{-1}$ (Fig. 5a). The estimates obtained using R2 did not show significant variations and appeared to decline when the measured methane fluxes increased (Fig. 5b). The CH4MOD model also produced a small averaged bias, representing $7.1 \%$ of the measured mean. The MSE was 253.0, 407.8, and $596.0 \mathrm{~kg} \mathrm{CH}_{4} \mathrm{ha}^{-1}$ for the M-S0, R2-S0, and R1-S0 scenarios, respectively (Table 2), which demonstrates that model performance improves when more factors are incorporated into the model.

Although the CH4MOD model produced better simulation results than the simple regression equations, its performance fundamentally depends on data availability. When no casespecific data were available (as in scenario $\mathrm{M}-\mathrm{S} 3$ ), $r_{\mathrm{b}}$ was $-32.2 \%$ and MSE was $122.1 \%$ of the mean flux; the results
Table 2. Performance of the methods under different scenarios of data availability.

\begin{tabular}{lrrr}
\hline Method & $\begin{array}{r}\text { Bias of the } \\
\text { estimation }\left(r_{\mathrm{b}}\right)\end{array}$ & $\begin{array}{r}\text { SD of the estimation } \\
\text { residues }\left(r_{\mathrm{v}}\right)\end{array}$ & $\begin{array}{r}\text { Root of } \\
\text { MSE (RMSE) }\end{array}$ \\
\hline R1-S0 & $212.0(62.1 \%)^{*}$ & $577.1(163.3 \%)$ & $596.0(174.7 \%)$ \\
R2-S0 & $-1.3(-0.4 \%)$ & $407.8(119.5 \%)$ & $407.8(119.5 \%)$ \\
R2-S1 & $-4.9(-1.4 \%)$ & $415.7(121.8 \%)$ & $415.7(121.9 \%)$ \\
M-S0 & $-24.2(-7.1 \%)$ & $251.8(73.8 \%)$ & $253.0(74.1 \%)$ \\
M-S1 & $-30.8(-9.0 \%)$ & $343.9(100.8 \%)$ & $345.2(101.2 \%)$ \\
M-S2 & $-120.7(-35.4 \%)$ & $341.3(100.0 \%)$ & $362.9(106.1 \%)$ \\
M-S3 & $-109.8(-32.2 \%)$ & $401.8(117.8 \%)$ & $416.6(122.1 \%)$ \\
\hline
\end{tabular}

* Percentages in parentheses indicate the magnitude of the error relative to the overall average methane flux $\left(341.2 \mathrm{~kg} \mathrm{CH}_{4} \mathrm{ha}^{-1}\right)$ for all cases.

obtained under this scenario were even worse than the results obtained under the R2-S0 scenario (Table 2). For the M-S1 scenario, where the data pertaining to the soil properties and water regime were case-specific, the magnitude of $r_{\mathrm{b}}$ decreased to $9.0 \%$ of the mean flux, and the MSE decreased to $101.2 \%$ of the mean flux. The M-S0 scenario produced much better results than the other scenarios since more data were available for the key model input variables (Table 2). Even no case-specific input data used in $\mathrm{M}-\mathrm{S} 3$ had smaller $r_{\mathrm{b}}, r_{\mathrm{v}}$, and MSE than R1-S0. In Table 2, larger $r_{\mathrm{v}}$ of R1-S0 than $\mathrm{M}-\mathrm{S} 3$ might come from the too simple explanation of 

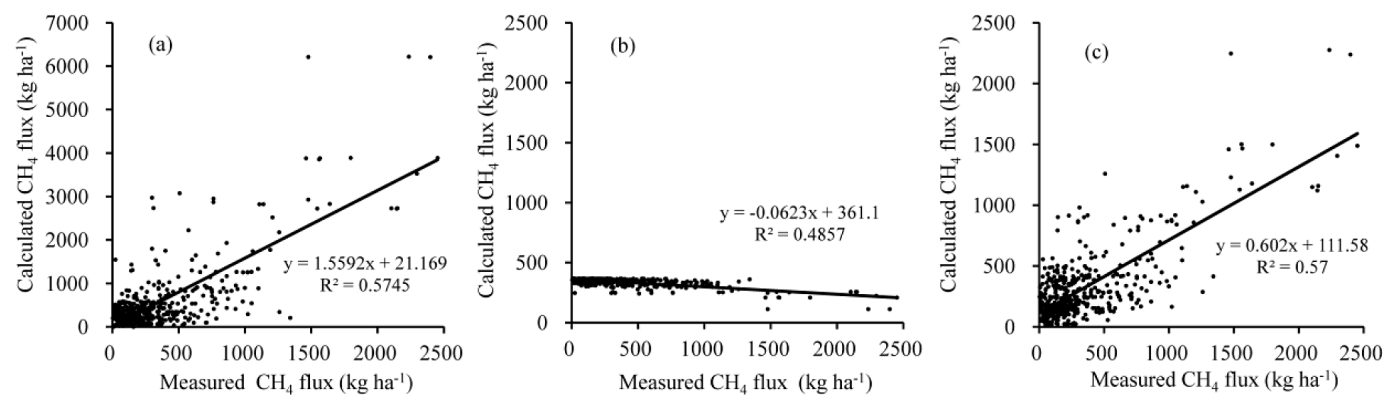

Figure 5. Methane fluxes in the experiments plotted against the respective simulation results through different methods. (a) R1-S0, (b) R2S0, and (c) M-S0, which are described in Table 1.
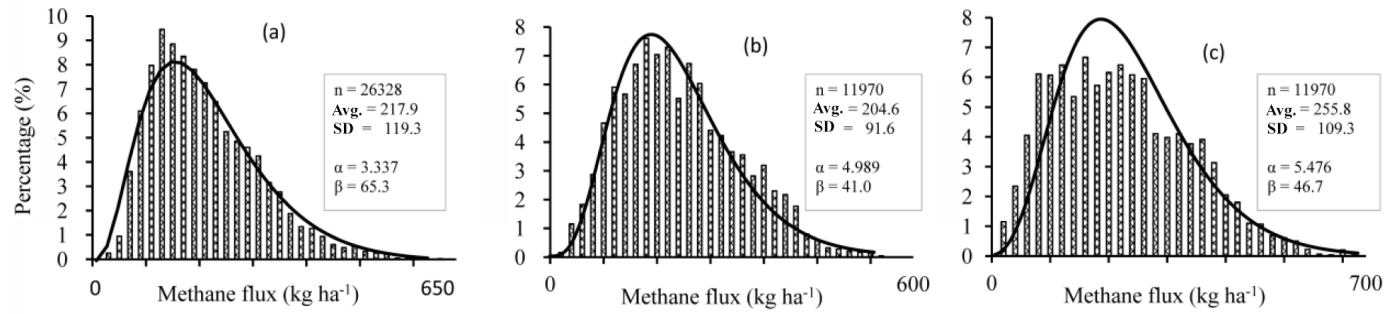

Figure 6. Histograms and their fitting gamma probability lines for the calculated methane fluxes (via CH4MOD) of the $10 \mathrm{~km} \times 10 \mathrm{~km}$ rice paddy grids in China. (a) Single rice rotations, including rice-fallow rotations, and rotations of rice with upland crops; (b) early and (c) late rice in double rice rotations. The vertical bars are the histograms of the calculated $F_{j}$ (Eq. 5), and the solid line is the theoretic gamma PDF line, the parameters for which were derived from the statistics for $F_{j}$ via momentum methods.

the influence from organic matter inputs on methane emission that added extra error to the estimation.

\subsection{Inventory of rice paddy methane emissions and the uncertainties with different approaches}

Because of the spatial heterogeneity in the climate and soil properties, organic matter incorporation, and field irrigation in rice cultivation, the methane fluxes simulated by CH4MOD varied spatially between 17.2 and $708.3 \mathrm{~kg} \mathrm{CH}_{4} \mathrm{ha}^{-1}$ from grid to grid (Fig. 6). The national means for the simulated methane fluxes were 217.9, 204.6, and $255.8 \mathrm{~kg} \mathrm{CH}_{4} \mathrm{ha}^{-1}$ for single, early, and late rice cultivation, respectively. The within-grid estimation error $\left(\sigma_{T, i}\right.$, calculated with Eq. 5) represented 81.2-95.5\% of the mean fluxes $F_{i}$ in the grids. In the present study, model fallacy, represented by $U_{\mathrm{b}, i}+U_{\mathrm{v}, i}$, contributed $79.5-88.9 \%$ to the uncertainty $\sigma_{T, i}^{2}$, with $\sigma_{\mathrm{d}, i}^{2}$ accounting for the remaining $11.1-$ $20.5 \%$. This implies that a model with better performance is needed to reduce the uncertainty of $\sigma_{T, i}$ in each grid.

As shown in Fig. 7, the highest levels of emitted methane occurred in southern China, with the northeast also representing a major source of methane, despite this region being climatically cool. The total amount of methane emitted, as calculated by the M-S0 approach, was 6.43 (3.79-9.77) $\mathrm{Tg} \mathrm{CH}_{4} \mathrm{yr}^{-1}$ (Table 3), which is close to the
7.51 $\mathrm{Tg} \mathrm{CH}_{4} \mathrm{yr}^{-1}$ derived from the experimental field measurements.

In Table 3, the estimated national $\mathrm{CH}_{4}$ emissions ranged from 6.43 (3.79-9.77) to 13.59 (1.45-38.98) $\mathrm{Tg} \mathrm{CH}_{4} \mathrm{yr}^{-1}$ for the M-S0 scenario and R1-S0 scenario, respectively. The $95 \%$ CIs of the national estimation differed more among the approaches than those among the data availability scenarios of each approach. With M-S0, the fallacy of CH4MOD contributed $56.6 \%$ of the total uncertainty, with the remaining $43.4 \%$ being attributed to errors and the scarcity of the spatial datasets of the model inputs (Table 4). As an indicator of the trade-off between the complexity of the approach and data availability, the $\sigma_{\mathrm{d}} / \sigma_{\mathrm{b}+\mathrm{v}}$ ratio in Table 3 was 0.87 for $\mathrm{M}-\mathrm{S} 0$, closer to 1 than those for the other approaches and scenarios, which also yielded the narrowest $95 \% \mathrm{CI}$ in Table 3 .

\section{Discussion}

\subsection{Contributions of different error sources to the uncertainties in the inventory}

In the experimental field measurements (Fig. 1), the variations in rice paddy methane fluxes ranged from 3.2 to $2451.7 \mathrm{~kg} \mathrm{CH}_{4} \mathrm{ha}^{-1}$, averaging $341.2 \pm 383.2 \mathrm{~kg} \mathrm{CH}_{4} \mathrm{ha}^{-1}$. The average simulated methane fluxes in the $10 \mathrm{~km} \times 10 \mathrm{~km}$ grids varied from 17.2 to $708.3 \mathrm{~kg} \mathrm{CH}_{4} \mathrm{ha}^{-1}$ (Fig. 6). The 
Table 3. Methane emissions inventory and the uncertainties caused by model imperfection and errors in model input data.

\begin{tabular}{lrrrrrr}
\hline Scenario & $\mathrm{CH}_{4}$ emission $(\mathrm{Tg})$ & $\sigma_{\mathrm{b}+\mathrm{v}}{ }^{*}$ & $\sigma_{\mathrm{d}}$ & $\sigma_{\mathrm{d}} / \sigma_{\mathrm{b}+\mathrm{v}}$ & $\sigma_{T}(\mathrm{Tg})$ & $95 \% \mathrm{CI}(\mathrm{Tg})$ \\
\hline R1-S0 & 13.59 & 9.89 & 1.11 & 0.11 & 9.99 & $1.45-38.98$ \\
R2-S0 & 10.37 & 2.74 & 0.14 & 0.05 & 2.74 & $5.71-16.39$ \\
R2-S1 & 10.24 & 2.91 & 0.07 & 0.02 & 2.91 & $5.83-17.16$ \\
M-S0 & 6.43 & 1.15 & 1.00 & 0.87 & 1.53 & $3.79-9.77$ \\
M-S1 & 7.94 & 1.89 & 0.97 & 0.51 & 2.13 & $4.33-12.62$ \\
M-S2 & 7.40 & 3.16 & 0.56 & 0.18 & 3.12 & $2.56-14.75$ \\
M-S3 & 9.23 & 3.79 & 0.00 & 0.00 & 3.79 & $3.37-18.01$ \\
\hline
\end{tabular}

${ }^{*}$ Root of $U_{\mathrm{b}}+U_{\mathrm{v}}$, uncertainty owing to model fallacy in the national inventory.

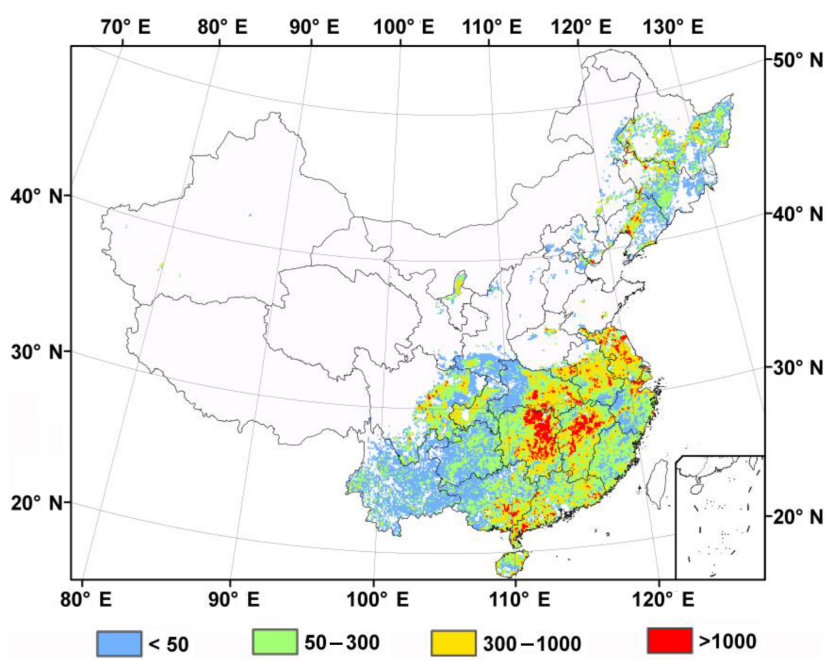

Figure 7. Spatial distributions of rice paddy methane emissions $\left(\times 10^{6} \mathrm{~g} \mathrm{CH}_{4}\right.$ per $10 \mathrm{~km} \times 10 \mathrm{~km}$ grid $)$.

extremely high methane fluxes obtained from experimental measurements were not reproduced by the model estimations. This was partly due to the discrepancy in the spatial representativeness of the methane fluxes in field observations and model estimations (Verburg et al., 2006). The experimental measurements represented methane fluxes from an area of less than $1 \mathrm{ha}$, while the modeled fluxes were the averages from $10 \mathrm{~km} \times 10 \mathrm{~km}$ grids. This mismatch in spatial representativeness might also be due to errors in the model input data as well as to the impacts of other unknown factors (Singh and Dubey, 2012; Bhatia et al., 2011; Zheng et al., 2010; Gauci et al., 2008). Methane emissions could be estimated using a limited number of factors and simplified equations to express the complex relationships between methane emissions and influential factors, but such simplification resulted in poor performance of the methods (Table 2). In Eq. (5), $\sigma_{\mathrm{d}, i}$ is the uncertainty due to errors in the input data. With an increasing number of explanatory factors, $r_{\mathrm{b}}$ and $r_{\mathrm{v}}$ might decrease (which means better performance of the method), but $\sigma_{\mathrm{d}, i}$ might increase because of the cumulative errors resulting from the increasing number of factors

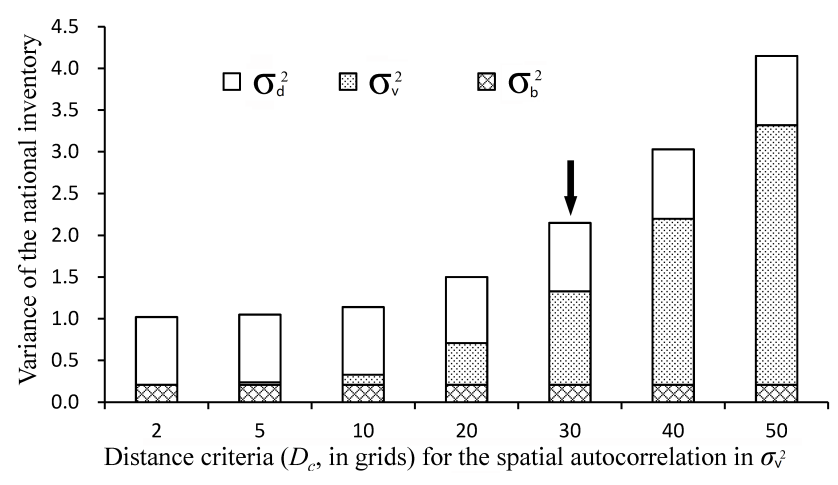

Figure 8. Composition of the aggregated uncertainty of the national inventory along with the spatial autocorrelation of the variances of the model residues in grids. Distance criteria $\left(D_{\mathrm{c}}\right)$ are used to define the step functions of spatial autocorrelation: if two grids diverge by a distance beyond $D_{\mathrm{c}}$, the autocorrelation is 0 ; otherwise, it is 1 . The step function is a simplified version and represents the upper limit of the true spatial autocorrelation. With the step function, a larger $D_{\mathrm{c}}$ indicates stronger autocorrelation.

incorporated in the models. To reduce uncertainties in the estimates and improve the performance of the model, the input data need to be available and of good quality.

The aggregated uncertainty of the national inventory depended not only on the magnitude of $\sigma_{\mathrm{v}, i}$ and $\sigma_{\mathrm{d}, i}$ in each grid (i) but also on the spatial correlation between these variables (Eq. S6 in the Supplement). The spatial correlation of $\sigma_{\mathrm{d}, i}$ depends on the availability of input data for the model and on spatial aggregation (Table S3 in the Supplement). However, the spatial correlation of $\sigma_{\mathrm{v}, i}$ could not be assessed analytically because it was a result of model fallacy and errors in measurements. In the case of a strong correlation of $\sigma_{\mathrm{v}, i}$ values, the aggregated $\sigma_{\mathrm{v}}^{2}$ will account for a large proportion of $\sigma_{T}^{2}$ (right side in Fig. 8). However, if the spatial correlation is confined to a short distance, such as less than four grids (Dormann et al., 2007; Dray et al., 2006), the contribution of $\sigma_{\mathrm{v}}^{2}$ to $\sigma_{T}^{2}$ will be negligible (left side in Fig. 8). At the midpoint of $D_{\mathrm{C}}$ (Eq. S6, 30 grids, equal to $300 \mathrm{~km}$ ), as shown in Fig. 8, the model uncertainty $\left(\sigma_{\mathrm{r}}^{2}+\sigma_{\mathrm{v}}^{2}\right)$ accounted for $56.6 \%$ of the uncertainty in $\sigma_{T}^{2}$ (Table 4 ). 
Table 4. Components of the uncertainty in the national inventory.

\begin{tabular}{lrr|r|rr}
\hline Rice & \multicolumn{2}{c|}{$\begin{array}{l}\text { Due to model } \\
\text { performance }\end{array}$} & $\begin{array}{r}\text { Due to data quality } \\
\text { and availability, }\end{array}$ & \multicolumn{2}{|c}{ Total } \\
& $U_{\mathrm{b}}$ & $U_{\mathrm{v}}$ & $U_{\mathrm{d}}$ & $U_{T}$ & $\sigma_{T}$ \\
\hline Early rice & 0.01 & $0.06(0.00-0.81)^{*}$ & 0.08 & 0.15 & 0.39 \\
Late rice & 0.01 & $0.10(0.00-1.28)$ & 0.05 & 0.16 & 0.40 \\
Single rice & 0.07 & $0.25(0.00-5.15)$ & 0.24 & 0.56 & 0.75 \\
All rice & 0.21 & $1.12(0.00-22.56)$ & 1.00 & 2.35 & 1.53 \\
\hline
\end{tabular}

* Numbers in parentheses represent the range of $U_{\mathrm{V}}$ depending on the spatial correlation of the model simulation residuals. Long-distance correlation results in a large aggregated $U_{\mathrm{v}}$, whereas short-distance correlation results in a small aggregated $U_{\mathrm{v}}$.

\subsection{Consistency of errors between model validation and model upscaling}

Upscaling a site-scale model (e.g., CH4MOD in this study) to a national scale poses enormous challenges when data are scarce. Enhancing the spatial abundance of the input data minimizes the propagation of data error into the aggregated uncertainties. Many environmental and agricultural factors impact methane emissions from rice paddies. In the CH4MOD model, the key factors were parameterized as model inputs (Huang et al., 2004). However, when assessing the uncertainty of a model, the explanatory variables are arbitrarily included (Verburg et al., 2006). Li et al. (2004) found that soil properties were the "most sensitive factor" and therefore used this parameter in the uncertainty analysis. The inclusion of as many of the highly sensitive key factors as possible in the uncertainty analysis should generate more accurate and reliable results (right part in Fig. 2).

Experimental field studies have shown that the rice variety has substantial impacts on methane emissions (Aulakh et al., 2008; Inubushi et al., 2011; Jia et al., 2002). A study of field observations ( $\mathrm{Su}$ et al., 2015) showed that transfer of the barley gene SUSIBA2 to rice favors the allocation of photosynthates to the aboveground biomass over allocation to the roots. Moreover, less biomass allocation to root exudates results in reduced methane emissions. The impact that the rice variety has on methane emissions was parameterized as the variety index (VI) in CH4MOD. According to Huang et al. (1998), VI ranges from 0.5 to 1.5 and averages 1.0 for most rice varieties. To validate the CH4MOD model (left portion of Fig. 2) using the 495 methane emission measurements included in the present study, VI was assigned a default value of 1.0 regardless of the rice variety because until now no dedicated attempts were made to quantify the VI of different rice varieties. Therefore, the $r_{\mathrm{b}}$ and $r_{\mathrm{v}}$ values presented in Table 2 incorporate the uncertainty in model performance that can be attributed to different rice varieties $\left(M_{\mathrm{f}}(x)\right.$ in Eq. S6 of the Supplement). To maintain consistency, VI was assigned the same default value (1.0) when the model was scaled-up to the national scale (right side of Fig. 2), and no PDF was built for the uncertainty calcula- tion conducted with the Monte Carlo simulation. If a PDF had been incorporated into the uncertainty calculation when the model was scaled-up, the overall uncertainties (Table 4) would have been overestimated. However, if different VI values were assigned to rice varieties during model validation, the error caused by the inaccuracy of VI would also need to be considered during the scaling-up of the model to prevent underestimation of the overall uncertainty.

\section{Conclusion}

Due to the remarkable spatial variation in rice paddy methane emissions, the uncertainties in national estimates obtained either through field measurements or modeling remain considerably large. For field measurements, the reduction in uncertainty achieved by increasing the number of observations was shown to be inversely related to the spatial correlation between the measurements. To reduce the estimation bias, the number of measured emission fluxes should be proportional to the paddy area where the corresponding agronomic activities and environmental conditions occur homogenously.

Model performance depends not only on the effectiveness of the models themselves but also on the availability of the data needed to drive the model. We found that without a sufficient quantity of high-quality data, a well-developed model may perform even more poorly than simple regression approaches. When modeling methane emissions, uncertainties in the performance of the model remain the major obstacle to reliably estimating methane emissions. Estimate uncertainty could be reduced at the national scale by increasing the availability of input data and decreasing spatial correlations among the residues of the model output.

Modeled by CH4MOD with all the available data, the national methane emission from rice paddies was 6.43 (3.799.77) $\mathrm{Tg} \mathrm{CH}_{4} \mathrm{yr}^{-1}$ in China. Compared to other options, balancing between the uncertainties caused by the model fallacy and data scarcity produced national estimations of the least total uncertainty. 


\section{Data availability}

The data of LUCC (land use and land cover change) were acquired from the Data Center for Resources and Environmental Sciences, Chinese Academy of Sciences (RESDC) (http://www.resdc.cn/data.aspx?DATAID=98). The climate data were provided by the Meteorological Data Service Center, Chinese Meteorological Administration (http://data.cma. $\mathrm{cn} /$ data/detail/dataCode/A.0029.0001.html). The data of rice cultivation (rice harvesting area and production) were retrieved from the agricultural yearbooks of China published annually by the China Agriculture Press. The dataset of soil properties is available at http://www.resdc.cn/data.aspx? DATAID $=146$, with the copyright dedicated to the Institute of Soil Sciences, CAS.

\section{The Supplement related to this article is available online at doi:10.5194/bg-14-163-2017-supplement.}

Acknowledgements. The study was jointly supported by the National Natural Science Foundation of China (Grant No. 41573069, $31370492,41321064)$.We greatly appreciate the helpful comments and suggestions from the two anonymous reviewers.

Edited by: P. van Bodegom

Reviewed by: two anonymous referees

\section{References}

Aulakh, M., Wassmann, R., and Rennenberg, H.: Pattern and amount of aerenchyma relate to variable methane transport capacity of different rice cultivars, Plant Biol., 2, 182-194, 2008.

Bachelet, D. and Neue, H.: Methane emissions from wetland rice areas of Asia, Chemosphere, 26, 219-237, 1993.

Bachelet, D., Kern, J., and Toelg, M.: Balancing the rice carbon budget in China using spatially-distributed data, Ecol. Model., 79, 167-177, 1995.

Banger, K., Tian, H., and Lu, C.: Do nitrogen fertilizers stimulate or inhibit methane emissions from rice fields?, Glob. Change Biol., 18, 3259-3267, 2012.

Bhatia, A., Ghosh, A., Kumar, V., Tomer, R., Singh, S., and Pathak, H.: Effect of elevated tropospheric ozone on methane and nitrous oxide emission from rice soil in north India, Agr. Ecosyst. Environ., 144, 21-28, 2011.

Bodelier, P. L. E. and Laanbroek, H. J.: Nitrogen as a regulatory factor of methane oxidation in soils and sediments, FEMS Microbiol. Ecol., 47, 265-277, 2006.

Butenhoff, C., Frolking, S., Li, C., Houweling, S., Milliman, T., Khalil, A., and Zhuang, Q.: Intercomparison of models to estimate methane emissions from rice agriculture using common data sets, 283, AGU Fall Meeting, 2009.
Butterbach-Bahl, K., Papen, H., and Rennenberg, H.: Impact of gas transport through rice cultivars on methane emission from rice paddy fields, Plant Cell Environ., 20, 1175-1183, 1997.

Cai, Z., Tsuruta, H., Gao, M., Xu, H., and Wei, C.: Options for mitigating methane emission from a permanently flooded rice field, Glob. Change Biol., 9, 37-45, 2003.

Cao, M., Dent, J., and Heal, O.: Modeling methane emissions from rice paddies, Global Biogeochem. Cy., 9, 183-195, 1995.

Cao, M., Gregson, K., Marshall, S., Dent, J., and Heal, O.: Global methane emissions from rice paddies, Chemosphere, 33, 879897, 1996.

CFPC: Datasets of China Pollution Source Census, China Environmental Sciences Press, Beijing, China, 2011.

Chen, H., Zhu, Q. A., Peng, C., Wu, N., Wang, Y., Fang, X., Jiang, H., Xiang, W., Chang, J., and Deng, X.: Methane emissions from rice paddies natural wetlands, and lakes in China: synthesis and new estimate, Glob. Change Biol., 19, 19-32, 2013.

Conrad, R., Klose, M., Noll, M., Kemnitz, D., and Bodelier, P. L. E.: Soil type links microbial colonization of rice roots to methane emission, Glob. Change Biol., 14, 657-669, 2007.

Dijkstra, F. A., Prior, S. A., Runion, G. B., Torbert, H. A., Tian, H., $\mathrm{Lu}, \mathrm{C}$., and Venterea, R. T.: Effects of elevated carbon dioxide and increased temperature on methane and nitrous oxide fluxes: Evidence from field experiments, Front. Ecol. Environ., 10, 520 527, 2012

Ding, A., Willis, C., Sass, R., and Fisher, F.: Methane emissions from rice fields: effect of plant height among several rice cultivars, Global Biogeochem. Cy., 13, 1045-1052, 1999.

Dormann, F. C., M McPherson, J., B Araújo, M., Bivand, R., Bolliger, J., Carl, G., Davies, R., Hirzel, A., Jetz, W., and Daniel Kissling, W.: Methods to account for spatial autocorrelation in the analysis of species distributional data: a review, Ecography, 30, 609-628, 2007.

Dray, S., Legendre, P., and Peres-Neto, P. R.: Spatial modelling: a comprehensive framework for principal coordinate analysis of neighbour matrices (PCNM), Ecol. Model., 196, 483-493, 2006.

EBCAY: China Agriculture Yearbook, China Agriculture Press, Beijing, China, 2006.

Gao, L. and Li, L.: Rice Meteorology and Ecology, China Agriculture Press, Beijing, 1992 (in Chinese).

Gao, X. Z., Ma, W. Q., Ma, C. B., Zhang, F. S., and Wang, Y. H.: Analysis on the current status of utilization of crop straw in China, J. Huazhong Agr. Univ., 21, 242-247, 2002 (in Chinese with English abstract).

Gauci, V., Dise, N. B., Howell, G., and Jenkins, M. E. Suppression of rice methane emission by sulfate deposition in simulated acid rain, J. Geophys. Res., 113, G00A07, doi:10.1029/2007JG000501, 2008.

Gaunt, J., Grant, I., Neue, H., Bragais, J., and Giller, K.: Soil characteristics that regulate soil reduction and methane production in wetland rice soils, Soil Sci. Soc. Am. J., 61, 1526-1531, 1997.

Goovaerts, P.: Geostatistical modelling of uncertainty in soil science, Geoderma, 103, 3-26, 2001.

Huang, Y., Sass, R. L., and Fisher Jr., F. M.: A semi-empirical model of methane emission from flooded rice paddy soils, Glob. Change Biol., 4, 247-268, 1998. 
Huang, Y., Zhang, W., Zheng, X., Li, J., and Yu, Y.: Modeling methane emission from rice paddies with various agricultural practices, J. Geophys. Res., 109, D08113, doi:10.1029/2003JD004401, 2004.

Huang, Y., Zhang, W., Zheng, X., Han, S., and Yu, Y.: Estimates of methane emissions from Chinese rice paddies by linking a model to GIS database, Acta Ecol. Sin., 26, 980-987, 2006.

Huang, Y., Zhang, W., Sun, W., and Zheng, X.: Net primary production of Chinese croplands from 1950 to 1999, Ecol. Appl., 17, 692-701, 2007.

Inubushi, K., Cheng, W., Mizuno, T., Lou, Y., Hasegawa, T., Sakai, H., and Kobayashi, K.: Microbial biomass carbon and methane oxidation influenced by rice cultivars and elevated $\mathrm{CO}_{2}$ in a Japanese paddy soil, Eur. J. Soil Sci., 62, 69-73, 2011.

IPCC (The Intergovernmental Panel on Climate Change): 2006 IPCC Guidelines for National Greenhouse Gas Inventories, prepared by: National Greenhouse Gas Inventories Programme, edited by: Eggleston, H. S., Buendia, L., Miwa, K., Ngara, T., and Tanabe K., Institute for Global Environmental Strategies (IGES), Japan, 2006.

Ito, A. and Inatomi, M.: Use of a process-based model for assessing the methane budgets of global terrestrial ecosystems and evaluation of uncertainty, Biogeosciences, 9, 759-773, doi:10.5194/bg9-759-2012, 2012.

Jia, Z., Cai, Z., Xu, H., and Tsuruta, H.: Effects of rice cultivars on methane fluxes in a paddy soil, Nutr. Cycl. Agroecosys., 64, 87-94, 2002.

Kennedy, M. C. and O'Hagan, A.: Bayesian calibration of computer models, J. R. Stat. Soc. B Met., 63, 425-464, 2001

Kern, J., Bachelet, D., and Tölg, M.: Organic matter inputs and methane emissions from soils in major rice growing regions of China, in: Soils and Global Change, edited by: Lal, R., Kimble, J., Levine, E., and Stewart, B. A., Advances in Soil Science, CRC Lewis Publishers, Boca Raton, 189-198, 1995.

Kern, J. S., Zitong, G., Ganlin, Z., Huizhen, Z., and Guobao, L.: Spatial analysis of methane emissions from paddy soils in China and the potential for emissions reduction, Nutr. Cycl. Agroecosys., 49, 181-195, 1997.

Khalil, M., Rasmussen, R., Wang, M. X., and Ren, L.: Methane emissions from rice fields in China, Environ. Sci. Technol., 25, 979-981, 1991.

Khalil, M., Shearer, M., and Rasmussen, R.: Methane sources in China: historical and current emissions, Chemosphere, 26, 127142, 1993.

Khosa, M. K., Sidhu, B., and Benbi, D.: Methane emission from rice fields in relation to management of irrigation water, J. Environ. Biol., 32, 169-172, 2011.

Legendre, P.: Spatial autocorrelation: trouble or new paradigm?, Ecology, 74, 1659-1673, 1993.

Li, C.: Modeling trace gas emissions from agricultural ecosystems, Nutr. Cycl. Agroecosys., 58, 259-276, 2000.

Li, C., Qiu, J., Frolking, S., Xiao, X., Salas, W., Moore III, B., Boles, S., Huang, Y., and Sass, R.: Reduced methane emissions from large-scale changes in water management of China's rice paddies during 1980-2000, Geophys. Res. Lett., 29, 1972, doi:10.1029/2002GL015370, 2002.

Li, C., Mosier, A., Wassmann, R., Cai, Z., Zheng, X., Huang, Y., Tsuruta, H., Boonjawat, J., and Lantin, R.: Modeling greenhouse gas emissions from rice-based production systems: sen- sitivity and upscaling, Global Biogeochem. Cy., 18, GB1043, doi:10.1029/2003GB002045, 2004.

Li, Y.: Research and practice of water-saving irrigation for rice in China, in: Proceedings of an International Workshop Held in Wuhan, edited by: Barker, R., Loeve, R., Li, Y., and Tuong, T., China: Water-Saving Irrigation for Rice, 23-25 March 2001 Colombo, Sri Lanka: International Water Management Institute, 2001.

Liang, G.: Rice Ecology, China Agricultural Press, Beijing, 1983 (in Chinese).

Liu, T. L., Juang, K. W., and Lee, D. Y.: Interpolating soil properties using kriging combined with categorical information of soil maps, Soil Sci. Soc. Am. J., 70, 1200-1209, 2006.

Ma, X., Zhu, B., Du, D., and Zheng, X.: $\mathrm{CH}_{4}, \mathrm{CO}_{2}$ and $\mathrm{N}_{2} \mathrm{O}$ emissions from the year-round flooded paddy field at fallow season, Journal of Agro-Environment Science, 24, 1199-1202, 2005 (in Chinese with English abstract).

Mao, L.: Irrigation in Rice Paddies, China Agricultural Press, Beijing, 1981 (in Chinese).

Matthews, E., Fung, I., and Lerner, J.: Methane emission from rice cultivation: geographic and seasonal distribution of cultivated areas and emissions, Global Biogeochem. Cy., 5, 3-24, 1991.

Matthews, R., Wassmann, R., and Arah, J.: Using a crop/soil simulation model and GIS techniques to assess methane emissions from rice fields in Asia. I. Model development, Methane Emissions from Major Rice Ecosystems in Asia, Nutr. Cycl. Agroecosys., 58, 141-159, 2001.

MWRUC (Ministry of Water Resources and Utilization of China): National Program for Conservation of Irrigation Water in Chinese Agriculture, in: Division of Rural Water Resources and Utilization, China Agriculture Press, Biejing, China, 1996 (in Chinese).

Mishra, S., Rath, A., Adhya, T., Rao, V., and Sethunathan, N.: Effect of continuous and alternate water regimes on methane efflux from rice under greenhouse conditions, Biol. Fert. Soils, 24, 399-405, 1997.

Neue, H., Becker-Heidmann, P., and Scharpenseel, H.: Organic matter dynamics, soil properties, and cultural practices in rice lands and their relationship to methane production, in: Soils and the greenhouse effect, edited by: Bouwman, A. F., Wiley, Chichester, 457-466, 1990.

Oberthür, T., Goovaerts, P., and Dobermann, A.: Mapping soil texture classes using field textuing, particle size distribution and local knowledge by both conventional and geostatisical methods, Eur. J. Soil Sci., 50, 457-479, 1999.

Ogle, S. M., Breidt, F., Easter, M., Williams, S., Killian, K., and Paustian, K.: Scale and uncertainty in modeled soil organic carbon stock changes for US croplands using a process-based model, Glob. Change Biol., 16, 810-822, 2010.

Penman, J.: Good practice guidance and uncertainty management in national greenhouse gas inventories, Institute for Global Environmental Strategies (IGES) for the IPCC, Japan, 2000.

Ren, W., Tian, H., Xu, X., Liu, M., Lu, C., Chen, G., Melillo, J., Reilly, J., and Liu, J.: Spatial and temporal patterns of $\mathrm{CO}_{2}$ and $\mathrm{CH}_{4}$ fluxes in China's croplands in response to multifactor environmental changes, Tellus B, 63, 222-240, 2011.

Sanchis, E., Ferrer, M., Torres, A. G., Cambra-López, M., and Calvet, S.: Effect of water and straw management practices on 
methane emissions from rice fields: a review through a metaanalysis, Environ. Eng. Sci., 29, 1053-1062, 2012.

Sass, R., Fisher, F., Turner, F., and Jund, M.: Methane emission from rice fields as influenced by solar radiation, temperature, and straw incorporation, Global Biogeochem. Cy., 5, 335-350, 1991.

Sass, R., Fisher, F., Wang, Y., Turner, F., and Jund, M.: Methane emission from rice fields: the effect of floodwater management, Global Biogeochem. Cy., 6, 249-249, 1992.

Sass, R., Fisher, F., Lewis, S., Jund, M., and Turner, F.: Methane emissions from rice fields: effect of soil properties, Global Biogeochem. Cy., 8, 135-140, 1994.

Sass, R., Fisher Jr., F., Ding, A., and Huang, Y.: Exchange of methane from rice fields: national, regional, and global budgets, J. Geophys. Res., 104, 26943-26951, 1999.

Sass, R. L. and Fisher, F. M.: Methane emissions from rice paddies: a process study summary, Nutr. Cycl. Agroecosys., 49, 119-127, 1997.

Shi, X., Yu, D., Warner, E., Pan, X., Petersen, G., Gong, Z., and Weindorf, D.: Soil database of 1:1,000,000 digital soil survey and reference system of the Chinese genetic soil classification system, Soil Survey Horizons, 45, 129-136, 2004.

Singh, A. and Dubey, S. K.: Temporal variation in methanogenic community structure and methane production potential of tropical rice ecosystem, Soil Biol. Biochem., 48, 162-166, 2012.

Smith, P., Martino, D., Cai, Z., Gwary, D., Janzen, H., Kumar, P., McCarl, B., Ogle, S., O'Mara, F., and Rice, C.: Greenhouse gas mitigation in agriculture, Philos. T. R. Soc. B, 363, 789-813, 2008.

Su, J., Hu, C., Yan, X., Jin, Y., Chen, Z., Guan, Q., Wang, Y., Zhong, D., Jansson, C., and Wang, F.: Expression of barley SUSIBA2 transcription factor yields high-starch low-methane rice, Nature, 523, 602-606, 2015.

Taylor, J. A., Brasseur, G., Zimmerman, P., and Cicerone, R.: A study of the sources and sinks of methane and methyl chloroform using a global three-dimensional Lagrangian tropospheric tracer transport model, J. Geophys. Res., 96, 3013-3044, 1991.

Thornton, P. E., Running, S. W., and White, M. A.: Generating surfaces of daily meteorological variables over large regions of complex terrain, J. Hydrol., 190, 214-251, 1997.

Tian, H. Q., Lu, C. Q., Ciais, P., Michalak, A. M., Canadell, J. G., Saikawa, E., Huntzinger, D. N., Gurney, K. R., Sitch, S., Zhang, B., Yang, J., Bousquet, P., Bruhwiler, L., Chen, G., Dlugokencky, E., Friedlingstein, P., Melillo, J., Pan, S., Poulter, B., Prinn, R., Saunois, M., Schwalm, C. R., and Wofsy, S. C.: The terrestrial biosphere as a net source of greenhouse gases to the atmosphere, Nature, 531, 225-228, 2016.

Van Bodegom, P., Wassmann, R., and Metra-Corton, T.: A processbased model for methane emission predictions from flooded rice paddies, Global Biogeochem. Cy., 15, 247-263, 2001.

Van Bodegom, P., Verburg, P. H., and van der Gon, H. A. C. D.: Upscaling methane emissions from rice paddies: problems and possibilities, Global Biogeochem. Cy., 16, 1014, doi:10.1029/2000GB001381, 2002a.

Van Bodegom, P. M., Verburg, P. H., Stein, A., Adiningsih, S., and Denier Van Der Gon, H. A. C.: Effects of interpolation and data resolution on methane emission estimates from rice paddies, Environ. Ecol. Stat., 9, 5-26, 2002b.
Verburg, P. H., van Bodegom, P. M., van der Gon, H. A. C. D., Bergsma, A., and van Breemen, N.: Upscaling regional emissions of greenhouse gases from rice cultivation: methods and sources of uncertainty, Plant Ecol., 182, 89-106, 2006.

Watanabe, A., Kajiwara, M., Tashiro, T., and Kimura, M.: Influence of rice cultivar on methane emission from paddy fields, Plant Soil, 176, 51-56, 1995.

Wei, H. P.: Statistical analysis of methane emissions from Chinese rice paddies from 1987 to 2010, Master, College of Resources and Environmental Sciences, Nanjing Agricultural University, Nanjing, China, 65 pp., 2012.

Weller, S., Janz, B., Jörg,L., Kraus, D., Racela, H. S., Wassmann, R., Butterbach-Bahl, K., and Kiese R.: Greenhouse gas emissions and global warming potential of traditional and diversified tropical rice rotation systems, Glob. Change Biol., 22, 432-448, 2016.

Xie, B., Zheng, X., Zhou, Z., Gu, J., Zhu, B., Chen, X., Shi, Y., Wang, Y., Zhao, Z., and Liu, C.: Effects of nitrogen fertilizer on $\mathrm{CH}_{4}$ emission from rice fields: multi-site field observations, Plant Soil, 326, 393-401, 2010a.

Xie, B. H., Zhou, Z. X., Zheng, X. H., Zhang, W., and Zhu, J. G.: Modeling methane emissions from paddy rice fields under elevated atmospheric carbon dioxide conditions, Adv. Atmos. Sci., 27, 100-114, 2010b.

Xie, G. H., Wang, X. Y., and Ren, L. T.: China's crop residues resources evaluation, Chinese J. Biotechn., 26, 855-863, 2010c (in Chinese with English abstract).

Xiong, Z., Cai, H., Min, S., and Li, B.: Rice in China, China Agricultural Science and Technology Press, Beijing, 1992 (in Chinese).

Yagi, K., Tsuruta, H., and Minami, K.: Possible options for mitigating methane emission from rice cultivation, Nutr. Cycl. Agroecosys., 49, 213-220, 1997.

Yan, X., Yagi, K., Akiyama, H., and Akimoto, H.: Statistical analysis of the major variables controlling methane emission from rice fields, Glob. Change Biol., 11, 1131-1141, 2005.

Yao, H., Conrad, R., Wassmann, R., and Neue, H.: Effect of soil characteristics on sequential reduction and methane production in sixteen rice paddy soils from China, the Philippines, and Italy, Biogeochemistry, 47, 269-295, 1999.

Zhan, M., Cao, C., Wang, J., Jiang, Y., Cai, M., Yue, L., and Shahrear, A.: Dynamics of methane emission, active soil organic carbon and their relationships in wetland integrated rice-duck systems in Southern China, Nutr. Cycl. Agroecosys., 89, 1-13, 2011.

Zhang, B. W., Tian, H. Q., Ren, W., Tao, B., Lu, C. Q., Yang, J., Banger, K., Pan, S. F.: Methane emission from global rice fields: Magnitude, Spatiotemporal patterns, and environmental controls, Global Biogeochem. Cy., 30, 1246-1263, doi:10.1002/2016GB005381, 2016.

Zhang, W., Yu, Y. Q., Huang, Y., Li, T. T., and Wang, P.: Modeling methane emissions from irrigated rice cultivation in China from 1960 to 2050, Glob. Change Biol., 17, 3511-3523, doi:10.1111/j.1365-2486.2011.02495.x, 2011. 
Zhang, W., Zhang, Q., Huang, Y., Li, T. T., Bian, J. Y., and Han, P. F.: Uncertainties in estimating regional methane emissions from rice paddies due to data scarcity in the modeling approach, Geosci. Model Dev., 7, 1211-1224, doi:10.5194/gmd-7-12112014, 2014.

Zheng, F., Wang, X., Lu, F., Hou, P., Zhang, W., Duan, X., Zhou, X., Ai, Y., Zheng, H., and Ouyang, Z.: Effects of elevated ozone concentration on methane emission from a rice paddy in Yangtze River Delta, China, Glob. Change Biol., 17, 898-910, 2010.
Zou, J., Huang, Y., Qin, Y., Liu, S., Shen Q., Pan, G., Lu, Y., and Liu, Q.: Changes in fertilizer-induced direct $\mathrm{N}_{2} \mathrm{O}$ emissions from paddy fields during rice-growing season in China between 1950s and 1990s, Glob. Change Biol., 15, 229-242, 2009. 